\title{
Accounting and Methodical Provision of Management Accountants in the Kaizen Concept
}

\author{
Elena Nikolaevna Klochko ${ }^{1}$ \\ Maria Sergeevna Rybyantseva² \\ Olga Michailovna Ignatova ${ }^{3}$ \\ Elena Anatolevna Yarushkina ${ }^{1}$ \\ ${ }^{1}$ Southern Institute of Management, \\ ${ }^{2}$ Kuban State Agrarian University, \\ ${ }^{3}$ Russian University of Cooperation Russian Federation; Email: magadan.79@mail.ru
}

Doi:10.5901/mjss.2015.v6n5s3p35

\section{Abstract}

This article describes the concept of kaizen, developed under the Russian accounting methodology. Theoretical propositions are presented in the context of the base and superstructure levels of kaizen, each of those are elements characterizing the concept-binders. Within the concept of kaizen change of terminology field is proposed, the transformation of the basic categories of management accounting - marginal income - from the position of the cash method. The effect of the proposed categories at the maintenance break-even analysis formulas, and rules decision-making management in the short term.

Keywords: kaizen, profit margins, break-even analysis, variable expenses.

\section{Introduction}

In the economic literature significant attention is paid to urgent problems of characteristics of kaizen. The studies of these issues are devoted to the works of AA Abrosimova, Baurinoy SB, Gerasimova MP, Kostyukova El, VV Shevtsova and many others. Kaizen interpretation reflected in their works, can be divided into groups:

1. Eliminating all types of losses in the production.

2. Constant gradual improvement in business processes without requiring large investments,

3. Method of the strategic target management.

4. Japanese philosophy and practice, based on continuous improvement, improving efficiency and creating motivation

An analysis of the nature and elements of kaizen allowed to formulate the following definition of the system "Kaizen is a method of targeted strategic management based on the thesis of the need to continuously improve and enhance the quality (indoctrination of business processes), a prerequisite for the application of which should be regarded as forming an essential operational information management".

\section{Methods and Materials}

Practical implementation of kaizen needs methodological support. With this Tse-Liu developed the concept of kaizen, providing two levels of review:

- The baseline kaizen - provides research, development and general theoretical systematization (approaches, interpretations, subjects, objects, principles and functions), structural (controlling and lean production) and teaching (Kaizen tools) elements of kaizen, a description of methodological foundations of the system;

- Top-Mounted level of kaizen reflecting the refraction of the basic provisions in real-conditions the functioning of the company, ie, translating theory into practice.

Thus, the concept of kaizen provides for the allocation of levels and elements of the system (Figure 1).

Theoretical elements of Kaizen are:

1. Approaches to kaizen: 
- Historical (kaizen - the basis of the Japanese "miracle");

- Subject-universal.

As part of the subject-fits-all approach can distinguish the following stages of development of kaizen: intuitive management accounting (up to XX century); Classic management accounting (the first third of the XX century); differentiation of types of management accounting (Kobersy, at al., 2015); parallel development of controlling (and differentiation of its species) to the quality management systematization and lean manufacturing; Kaizen in the modern sense.

2. Interpretations kaizen.

3. Subjects and objects of kaizen.

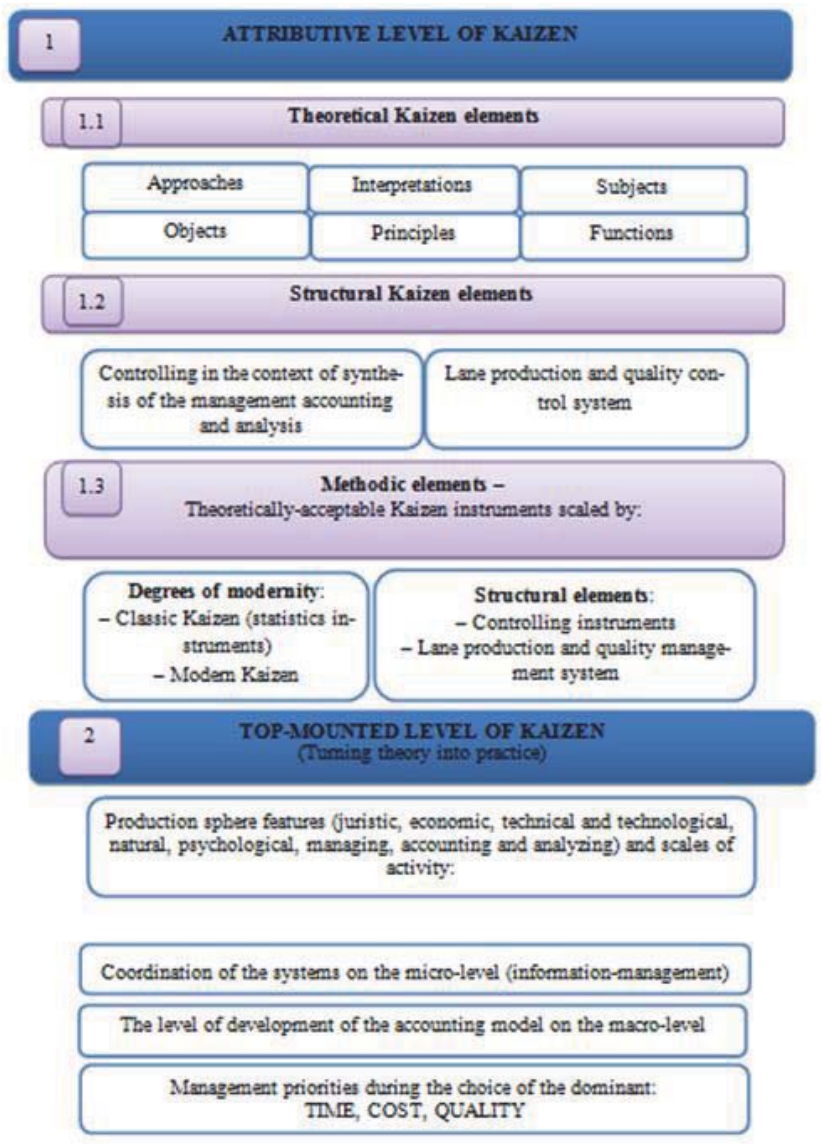

Figure 1. The concept of kaizen

4. kaizen principles (integrity, hierarchy and feedback; duration and consistency; on the basis of mentality in the universal approach, a new quality of leadership, process thinking, eliminate stereotypes, control deviations from the standard process, the dynamic changes of tools and targets, identification and personalization; the principle of "baton").

5. Functions of kaizen (counter entropy, the fight against the inertia of thinking, development of creativity, the balance between the maintenance and improvement, concretization techniques).

As part of the superstructure level the following provisions are viewed:

I. Level of accounting model on the macro level.

The ability to implement kaizen tools depends on the level of the accounting model as well as the state of the 
economy. The economic situation determines the concentration of divergence optionally-management effort in a particular area (for example, OJEC cookies solvency).

The main characteristics of any user model can be considered:

- The presence of the priority interests of certain sectors of the economy (for example, reflected in the Russian balance sheet items "material search assets" and "intangible assets search");

- The degree of orientation of the fiscal accounting;

- The level of regulation and policy accounting methods;

- The impact of the professional organizations in the accounting process, the possibility of participating in the accounting lawmaking;

- The existence of a single chart of accounts;

- The purpose of accounting and reporting;

- $\quad$ "Real" users reporting and accounting information (category Custom-lei actually requesting financial statements);

- The possibility of using official accounting methodology for the management;

- The gap between the declared characteristics and the model Historically, Misia features;

- The existence of a political or religious ideology tough.

Depending on the combination of features stand out:

- Anglo-American model;

- Continental model;

- South American model;

- Islamic model;

- International model (theoretical construct, since the interests of the transnational corporations can be implemented within the framework of the Anglo-American and Continental-term models).

In the economic literature describes the experience of the application of Kaizen in the United States and Japan, ie under the Anglo-American and Continental models, respectively. Russia also belongs to the continental model, so the Japanese experience is closer to it.

It should be noted that the patterns reflect the specific characteristics of the "official" accounting and kaizen management method is an example, to a lesser extent depending on the specific model. From these positions, Kaizen can be applied for South-American (Latin American) model (Umarov, 2013, Magsumov, 2013 \& Karepova, et al., 2015). Kaizen in the classic version is impossible to apply in the presence of rigid religious or political ideology (eg, within the Islamic model). Thus, the existence of Kaizen involves a certain degree of freedom. Specifics of accounting model defines the characteristics of kaizen, outlines its goals and objectives, options for interaction with the official accounting methodology.

II. Industry features and scope of activities.

III. Priorities guidance in selecting the dominant: time, cost, quality (both reachable only two indicators). In this regard, all running the building project organization can be divided into three groups. For the first group of the main projects to determine the performance of the required amount of work in a tightly specified period to meet high quality requirements, which, of course, cause an increase in the value (except for the use of solid contract prices).

The projects of the second group is characterized by minimum time of work performance and well-JCOMM agreed price (without the possibility of its adjustment), which inevitably leads to reduced quality. Some easing of requirements to quality does not negate the need for compliance with the law.

When the draft of the third group focuses on the quality and cost is not a motivating factor, this situation leads to delays in the implementation of the project (in the absence of non-price factors, requiring its timely implementation).

Depending on which group is the most by the Organization of projects, we can talk about the value orientation of the top management of the organization.

If any value orientation should be evaluated activity computer-SRI in two directions:

a) Assessment of the value stream;

b) The profile of the product value (order).

Map the value stream involves assigning main processes and you-are being done one of the following statuses:

1. value-adding to fulfill orders (in the context of a competition benefits and reduce defects);

2. Does not add value, but necessary for the functioning of the organization (management infrastructure, in particular, accounting);

As a rule, this type of process and work with the client's position does not add value to carry out orders, but is 
needed in the framework of the functioning of the organization in the perimeter of the legal framework of the certain state (which does not preclude a number of attempts to minimize the cost of this group). According to Michael George, this type of processes and operations can be described with the following questions:

- Does the performance of this work the law or other rules?

- Does this work to reduce financial risk?

- Whether this work is to comply with financial reporting requirements;

- Does it violate any production process, if work is not done? (Grinin, 2012 \& George, 2011).

3. Does not add value, the implementation of which is not necessary to fulfill the order. This type of work can relate to one of the operations: processing, multiple signatures, counting, inspection, changeover, downtime, displacement, delay, storing.

There may be used different approaches when assessing the role of the processes in the value stream. For example, in the work of Brian Maskell and Bruce Baggaley "The practice of Lean Accounting" is shown in gradation depending on the rating of "costs for the company - value for the customer" for each process (Maskell, 2013), carried out diagonal "optimal" this relationship.

The graduation process in accordance with the criterion of "cost - value" allows to point out four groups:

- High value for the customer - lower costs;

- High value for the customer - high costs;

- Low value for the customer - lower costs;

- Low value for the customer - higher cost.

Clearly, carrying such a gradation is carried out for the development of the strategy depending on the positioning of above or below the diagonal. For example, the rating process' costs low, low value ", located below the diagonal of the" optimal "decision can be made about their elimination (eg purchase from a third-party outside the perimeter of the value stream).

The process of implementing Kaizen is greatly simplified by the use of the analytic-cal instrument as "profile value of the product (order)", the following functions:

- Conformity assessment order requirements customers;

- A comparison with competitors;

- Design changes.

Formation of the "Profile of product value (order)" occurs in stages (compiled, but on the basis of (RasskazovaNikolaev, 2013):

1) formation of the list of properties (features) that are important to customers;

2) ranking of the properties within the framework of a particular group. Most often, the use-form a weights ranging from 0 (the importance of the properties is minimal) to 1 (a property nai-highest importance). Keep in mind that the ranking of the properties held for each project assigned to rank individual and depends on a group project (ie priority characteristics);

3) the formation of a list of indicators that reflect the properties;

4) The definition of "standard" values of indicators, ie value sufficient in the opinion of the client; It should clearly define the boundaries of sub regulation, ie once was spoken outline the list (types of standards), the valuation of which this subsystem controls.

According to E. Dobrowolski as standard can be any index, which is used to plan costs and analyze the reasons for the deviation Fact cal values of the planned expenditures E. Dobrovolsky (2008).

5) comparing the reality ("normative") with the give values, the search for the causes of deviations, and the ways of eliminating the culprits.

IV. Coordinated systems at the micro-level (in particular, the interrelationships between information flow and management efforts), the use of synergies. In this context, synergy - is summarizing the effect of the interaction of two or more factors, characterized by the fact that their effect is much greater than the effect of each individual component in the form of a simple sum.

In considering coordination systems needed in particular to pay attention to:

a) the availability of balanced information flows, mobility management reacting to the impact;

b) the adequacy of the system of material incentives.

Within the framework of the implementation of kaizen it is obvious that the information component of workers' activity (preparation and timely provision of information) should be part of the variable component of the salary fund, or the system of material stimulating in the form of bonuses (or fines).

If wages in the organization consists of variable and fixed parts, in case of non essential information (untimely 
submission of) the possibility HN following decisions within the reporting period:

- $\quad$ The first time - a fine (from 5 to $10 \%$ of the variable part);

- $\quad$ Second - $50 \%$ of the variable portion;

- The third - depriving the variable part (the right to veto should be given to the accounting office or analytical department depending on the purpose and importance of the information).

Obviously, the list of essential data as well as the timing of their submission must be spelled out in the job descriptions of employees.

Quality indicators can be divided into levels:

- $\quad$ The primary indicator of quality (description);

- Secondary quality indicator (engineering characteristics which affect the primary indicators of quality).

When using material incentives in the form of bonuses (bonus de) principle is the same. Although it can be used with more rigorous approach at the manager's will. The indexes can be defined the following conditions for the reward:

- Compliance with the requirements for the provision of data reporting delivery by the controlled performance (time and required disclosure of indicators);

- Compliance with the terms of work;

- Compliance with the cost of the work.

It should be noted that the number of control indicators often includes indicators of costs. Consider the disadvantages of this indicator, in the work of William Laro "Office Kaizen" it is set that most traditional managers and organizations are trying to deal with the losses by controlling costs (by reducing them). Since the majority of surface loss is directly related to the processes, while reducing the cost to clearly reduced, not only loss, but also the amount of work required. The cost management is insufficient; it is too late, too far, difficult and abstract. Management should require that no figures were extracted from the costs of a cause-and-effect diagrams that identify the reasons for the level of direct costs on the job Laro (2009). In this context, the rate of cost should not dominate in the formation of the material incentive fund.

In forming material incentives in the framework of kaizen one must use the Pareto principle. Pareto chart - a tool that helps co-focal point on issues that have the greatest potential for improvement. As resources are limited in all companies, should be addressed to the decision of the most important pro-problems (Umarov, 2013).

In accordance with the principle of Pareto, concentrating on processes vital for the organization gives greatest impact on the achievement of goals and required results. Hence typically $20 / 80$ : concentration $20 \%$ of the time on the most important problems that can result in $80 \%$ of the results. The remaining $80 \%$ of the time provide only the remaining $20 \%$ of the results. The essence of the principle: the main room for improvement is usually associated with very few problems.

In the formation of the Pareto principle of kaizen is used quite often in different ways:

1) A rigid grading staff. Relatively speaking selection: kaizen footage (most valuable for the company employees), the inertial mass, "muda" (category co-nicks, not consistently giving effect on the activity).

Regarding personnel principle is as follows:

1. $20 \%$ of the staff (kaizen staff - employees, bringing substantial benefits) allowed to reach $80 \%$ of the results;

2. $80 \%$ of the staff (potentially useful, and does not benefit the group of co-employees) reach only $20 \%$ of the results.

Obviously, the concept of "value" contains the employee a fair share of subjectivism. In this aspect, the employee is considered as an impersonal human resource with a number of characteristics. The approach to its valuation can be taken from the international financial reporting standards on the criteria of value (importance) of information. In fact, the value of the employee can be determined similarly to the materiality of the financial information:

The value of the worker must have not only quantitative (usually expressed in value terms), but the quality content (including consideration of "past" merits);

- $\quad$ The described employee is of considerable value, if the cease of his work entails a certain loss for the company.

2) Responsibility for $80 \%$ of the errors lies with the leadership and the system, and $20 \%$ on the use, NITEL M. George (2011). Nevertheless, one should not underestimate the role of staff, and the framing-rate policy is necessary to remember one of the most important tenets: list of personnel expenses is much wider labor costs and social charges. Related personnel costs can be divided into five groups (Rasskazova-Nikolaev, 2013 \& Novikov, et al., 2015):

1. Costs directed to legal and physical capabilities of using one`s staff:

- To find in the labor market and selection of personnel; 
- The execution of the employment relationship with the employee, taking care of the juristic issues;

- For the primary movement of personnel to and from work (if the staff is geographically removed at the time of hiring).

2. Costs for the initial training of staff to use and further maintenance of such readiness (Magsumov, 2015):

- On the "gear" recruits material resources - Difficult, you're on clothing, protective equipment, workplace equipment, etc.;

- for initial training.

3. The costs of operating personnel:

- Labor costs with deductions;

- The cost of staff meals;

- By regular delivery personnel to the workplace.

4. The cost of rehabilitating the staff: the cost of annual medical examination, treatment, payment, leave, etc..

5. Costs of disposal personnel:

- The costs of severance pay;

- Payments made to a former employee by a court decision;

- Downtimes and losses caused by massive layoffs of employees.

Thus, forming a cadre should take into account the entire associated costs-workers-with, not just wages with deductions. And speaking of "objectivity" paid wages; salaries should be compared with the result that provides the employee.

Reasonable personnel policy provides for the reasonableness of the reasons for dismissal of employees. When working with staff layoffs are inevitable if:

- Negative mood employee who brings discord in the community;

- Misconduct, theft, use of alcohol;

- $\quad$ Lack of confidence (possible compensation employees who must be fired at the expense of the top manager of the unit in the proof of his errors in assessing the quality of an employee at the stage of receiving it to work);

- The economic crisis (as an option, part-time for 50\% co-composition of the company, dismissal with compensation).

Guarantees for staff, provided by kaizen, focused on kaizen frames. Introducing social security (other than those required by the Labour Code), for the categories of the inertial mass and "muda" seems irrational.

One of the most pressing issues in the formation of the material stimulation is indicators that make up the fund bonuses. Typically, these are indicators include cost savings in comparison with the norm. The problem is a gap between the goals of subdivision (maximization of the fund awarding any cost) and the company's strategic objectives (to achieve the required quality indicators). The solution is a prerequisite pass quality control. le the economy - it is a necessary condition for the bonus, but only compliance requirements, the quality is sufficient, the fulfillment of which makes the award possible. The increasing complexity of the conditions for obtaining the award requires increasing the fund bonuses. For example, when a substantial savings are in compliance with the quality requirements, the unit (or employee if the individual types of work) receives $30 \%$ of the savings.

Thus, the concept of kaizen involves consideration of two levels: basic and superstructure that allows within the subject-fits-all approach to conduct the structuring of its elements reflect the interrelation and mutually-of methodological bases and practical methods of kaizen.

Kaizen system involves changing the established management approaches, techniques, terminology. Consider the example of critical thinking applied in the administrative practice categories.

The Federal Law "On Insolvency (Bankruptcy)" (Article 3 of "Signs of the bankruptcy") is defined: "A legal entity is considered to be unable to meet the requirements-of creditors on monetary obligations and (or) to fulfill the obligation to pay Binding payments if relevant obligations and (or) the obligation not fulfilled them within three months from the date when they should have been done "( On Insolvency (Bankruptcy): Federal Law of the Russian Federation dated October 26, 2002 № 127-FZ as amended on 01.12.2014, № 405-FZ). In such a Zoom, the main criterion for bankruptcy is the imbalance of cash flows, rather than a negative financial result. However, in terms of the dominant method of calculating, the most important indicators associated with measures calculated under the accrual basis (for example, profit margins).

This approach is not unique to the financial, but also for counting management. An example can be considered one of the most significant indicators of managerial accounting - profit margins.

In accordance with the well-known formula, profit margin is the difference between revenue and variable costs. In today's economic environment construction organizations often do not get the revenue, or do not get it in full. Therefore, 
for the purposes of the application of the accrued revenue management as an analytical indicator is not always informative.

Variable costs represented mainly wage workers, piece workers, or the variable part of remuneration (by dividing the change in the variable and constant parts in accordance with the accounting policies of the organization), on the technological objectives, building materials and others. At the same time, the organization may be, unpaid debts to suppliers, on wages. In fact, while the exponent-variable costs, calculated on an accrual basis does not disclose information in full.

In this regard, it is recommended to count "paid variable costs":

1. Material costs:

- Paid for variable costs: direct costs accrued, multiplied by averaging the percentage of US-payment of accounts payable;

- Paid fixed costs: Accrued overhead costs, multiplied by the average interest payment of accounts payable.

2. Labour costs:

- Paid for variable costs: wages paid workers, piece workers, or the variable part of remuneration (payment of labor, involving two parts: solid (guaranteed), and the variable part of the salary);

- Paid fixed costs: salaries paid workers time-worker or a permanent part of remuneration (payment of labor, involving two parts: a fixed salary and variable part).

3. Other costs:

- Paid variable costs accrued variable costs multiplied by the average interest payment of accounts payable;

- $\quad$ Paid fixed costs: the fixed costs accrued, multiplied by the average interest payment of accounts payable.

Average percentage of payment of accounts payable is paid share payable for the period in its accumulated value.

Obviously, a part of the costs not reflected depreciation, which do not involve cash flows, and are the result of applying the accounting methodology. As part of the amortization only depreciation accrued related to the variable costs only by the method of depreciation is proportional to the volume of goods (works). According to the study of methods of depreciation used by the building organizations, it concluded an extremely rare application of this method. In this regard, as part of the variable costs, depreciation charges we can be neglected as insignificant. Most organizations prefer to use a linear way to minimize the differences with the tax accounting.

Differences between costs generated in accordance with the accrual and cash basis, are not only in the presence of depreciation. In addition to the depreciation has a number of articles that are included in the budget revenue and expenditure (Me-Todd charges) and are not included in the budget funds, the articles of which are formed on a cash basis:

- The accumulation of accounts receivable;

- Depreciation;

- Revaluation of fixed assets and inventory items;

- Marriage in the production;

- Damage and loss reserves during transport and storage;

- $\quad$ The results of the inventory shortage;

- Exchange differences.

Thus, the marginal income from the perspective of the cash method can be calculated as a result of comparing proceeds (collection of debitor debt) and variable costs paid.

For the structuring of terminology can be used the following concepts:

- Profit margins under accrual accounting;

- Profit margins in the cash method.

The economic sense of marginal income when cash method means the amount that can be used to repay the fixed costs payable (excluding accounts receivable payments and other similar costs).

Practical application is to increase the validity of the rules of management decision-making in the short term, based on the category of "marginal profit". For example the rule of deciding to end unit's or some other particular activity. In the context of accrual positive profit margins cannot be a reliable indicator without calculating the marginal income in the cash method.

In addition, the financial indicators in the short run may be considered after-following:

1. Percentage of payment of variable costs - the ratio of variable costs paid to their total accumulated value. If the amount of depreciation calculated according to the method of depreciation in proportion to the volume of 
production (work) is essential, then the formula becomes: the ratio of variable costs paid to their total chargedterm value (excluding depreciation, calculated according to the method of depreciation in proportion to the volume of goods (works). In the absence of wage arrears coincides with the average interest payment of accounts payable.

2. Interest payment of fixed costs - the ratio of fixed costs paid to their total assessed value (excluding permanent depreciation calculated on the straight-line method, the declining balance, sum of numbers of years of useful life, and other similar costs).

The calculation involves several additional categories of information on other complements-budget funds generated for management purposes. The currently used form of the statement of cash flow reveals the following board Ms. within cash flows from operating activities:

- Suppliers (contractors) for raw materials, work and services;

- In connection with the compensation of employees;

- Interest on debt;

- Corporate income tax;

- Other payments.

For management purposes, you can transform some positions presented. To improve analytic You can specify the ability to control the direction of the Organization incurred by the magnitude of variable and fixed costs for the groups: material costs, labor costs and other expenses. le indicate generally the group, depending on whether or not the cost of the administrative impact of the head of the organization. Or the costs caused by environmental factors and the impact of administrative head of the department-term company can not adequately affect their value.

Coverage indicators presented depends on the scale of the organization. For a small construction company information can be used on all the activities-sti for larger - in the context of major projects. This approach can be regarded as pre-drill at the management level, in the context of profit centers and others.

Implementation of a marginal income in the cash method will lead to the transformation formulas break-even analysis (Table 1).

Table 1. Formula break-even analysis

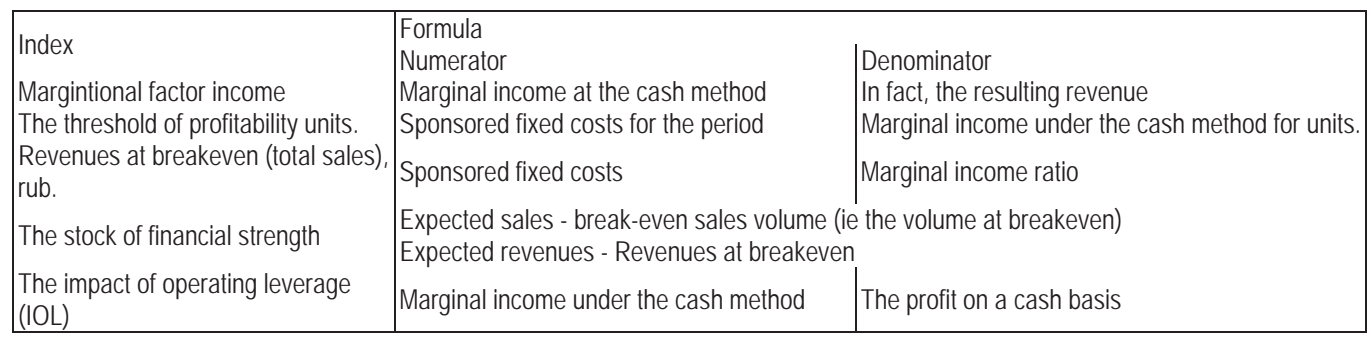

Use of cash method illustrates the emergence of a more "serious" consequences change in revenue, even by $1 \%$ (ie a significant change in profit on sales), which makes it necessary to make informed management decisions in the field of pricing and changes in sales revenue.

Implementation of a marginal income in the cash method will also result in a change of rules and decision-making in the short term:

1) Preference should be given to the other side of activity (products or services), which brings the maximum profit margins in the cash method, based on the one unit of limiting factor.

2) The decision on termination of activity:

- As long as the production has a positive profit margin in the cash method, you should not suspend the release of these products;

- As long as the structural division of the company gives a positive marginal income with the cash method, you should not stop its activities.

With a sharp increase in the cost of works (ie, any manifestation of the loss of control over costs), the main emphasis should be on determining the list of controlled and uncontrolled liabilities. In this case, in the basis for the division of costs the classification of costs in relation to changes in production volume will not be put, and their possible gradation control (regulation). It should pay particular attention to assessing the overhead from this position. 
The list of expenses included in 'overheads' is given in Appendix 1 to the methodical recommendations on the calculation of the value of overhead when determining the value of construction products (Guidelines for the calculation of the value of the overhead of defined-dividing the value of construction products: approved. Letter of the Ministry of Construction of the Russian Federation dated October 30, 1992 № BF-907/12 \& Wheeler, 2009). Based on the above, in this normative document list should be established Rules of differentiation costs controllability.

On the basis of the Rules of differentiation costs controllability can be formed another indicator of marginal income - control margin. from sales.

This figure may be determined by the formula: Revenue minus controlled liabilities or uncontrolled ones plus profit

In addition, the index can be calculated - controllability cost of organization, which is a proportion of controllable costs in their total value.

\section{Concluding Remarks}

Thus, the kaizen system provides some transformation of the category unit, depending on the priority tasks. If the complexity of the organization in matters of pay, it is necessary in the financial indicators include a profit margin in the cash method. If you need to provide ensured control over the dynamics of changes in costs, the margin is determined by the control.

In addition to the proposed indicators should conduct a critical assessment of the used financial indicators. Disadvantages of the traditional indicators are described in Brian Maskell and Bruce Baggaley "Lean Accounting Practice" B. Maskell (2013). They stimulate on-accumulation of stocks. Indicators are formed with a delay with respect to the decision point, contain mainly financial data; lead to large losses of time required for data collection.

For example, when assessing the long-term solvency ratio we use the method of general liquidity, which is used in calculating the index of "Inventories" in current assets. The logic of this indicator contradicts the basic idea-pits kaizen. To meet the standard value ratio, sufficiently precisely, maximize inventory balances at the period end. From the perspective of user's solvency it is characterized positively, but in reality, the company would suffer significant harm: excess reserves will lead to an increase in fixed costs and, consequently, to a decrease in profits. Thus, in accordance with the kaizen, the calculation of the current ratio from the excess reserves should be excluded, the amount of which is calculated by experts depending on the specific production process.

According to Brian Maskell and Bruce Baggaley, it is advisable to use the cash method, which "gives the desired effect in the form of increased profitability while reducing inventory levels and a decrease in profitability with an increase in inventory levels. It gives the reverse effect compared with statements on an accrual basis, but is highly desirable from the standpoint of lean manufacturing. In this context, to improve the reliability of the turnover rates may be offered the option, under which the calculation is used not charged, and the resulting revenues.

The basic idea of the examples described changes categorical apparatus - Kaizen provides a permanent job not only on technology but also on information-systems of. Rigid pad formed in the middle of the last century category should not be used in an unaltered form. The modern world demands constant changing the dynamics and development. All this is made possible by the adoption of Kaizen as a basic concept of management within the system of management accounting.

\section{References}

Grinin, A.J. (2012) plant management style kaizen: How to reduce the costs and profits rose-Sit / A.Y. Grinin. M.: Alpina Publisher. pp. 189.

Novikov, V.S., Klochko, E.N., Yarushkina, E.A., Zhukov, B.M. \& Dianova, V.A. (2015) On peculiarities of the virtual economy of modern Russia: categories, virtual relationships, educational constructs. Mediterranean Journal of Social Sciences, 363 (247-257).

George, M. (2011) Lean plus Six Sigma in services. Like MSE-rate lean and Six Sigma quality improvement helps busi-sa / M. George Lane. from English. T. Gutmann. M.: Mann, Ivanov and Ferber. pp. 464.

Dobrovolsky, E. (2008) Budgeting step by step / AE Dobrovolsky, B. Karabakh-new, P. Borovkov, E. Glukhov, E. of Breslau. St. Petersburg: Peter. pp. 448.

Laro (2009) The US Office Kaizen: Transforming office operations into a strategic pre-Estate / D Laro, trans. from English. AG Pyatkevich. - Minsk: Grevtsov Pablisher. pp. 224.

Maskell, B. (2013) Practice Lean Accounting: management, financial accounting and ICI theme lean enterprise reporting / BI Maskell, B. Bagan. Trans. from English. - M .: Institute tute for Complex Strategic Studies. pp. 384.

Karepova, S.G., Karabulatova, I.S., Klemovitsky, S.V., Novikov, V.S., Stratan, D.I. \& Perova, A.E. (2015) New approaches to the 
development of methodology of strategic community planning. Mediterranean Journal of Social Sciences, 363 (357-363).

Kobersy, I., Barmuta, K., Muradova, S., Dubrova, L., \& Shkurkin, D. (2015). The System of the Methodological Principles of Management of Enterprise Development. Mediterranean Journal Of Social Sciences, 6(3 S4), 25. Retrieved from http://www.mcser.org/ journal/index.php/mjss/article/view/6707

Guidelines for the calculation of the value of the overhead of defined-dividing the value of construction products: approved. Letter of the Ministry of Construction of the Russian Federation dated October 30, 1992 № BF-907/12. - System GARANT 2014.

Magsumov, T. A. (2015). The additional professional training in the late Russian Empire. Bylye Gody, 36(2), 327-337.

Magsumov, T. A. (2013). Educational excursions in technical schools of pre-revolutionary Russia. Bylye Gody, 27(1), 52-60.

On Insolvency (Bankruptcy): Federal Law of the Russian Federation dated October 26, 2002 № 127-FZ (as amended on 01.12.2014, № 405-FZ]. - Cictema GARANT 2014

Rasskazova-Nikolaev, S.A. (2013) Management accounting: Textbook / SA RASSC-Call-Nikolaev, S.V. et. All. St. Petersburg: Peter. pp. 496.

Umarov, H.S. (2013) The basic models of accounting and reporting in the world / H.S. Umarov // Audi-tor. № 6. pp. 95 - 97.

Wheeler, D. (2009) Statistical Process Control: Optimization of business with use of either Shewhart control charts / D. Wheeler, D. Chambers; Trans. from English. M.: Alpina Bize-carrying Books. pp. 409. 